Results: The prevalence of LUTs was $62 \%$. The commonest symptoms were frequency (43\%) and stress incontinence (49\%). It was significantly associated with BMI, past obstetric history, menopausal status and previous pelvic surgery. Storage symptoms including stress urinary incontinence (SUI) and overactive bladder (OAB); and voiding dysfunction also shows significant associations. For SUI, the subject's race, hormonal therapy status and smoking history were not significant. For OAB, other than race, HRT and smoking, BMI was also not significant. For voiding dysfunction, other than HRT and smoking, parity and menopausal status were also not significant.

Conclusion: This study shows that LUTS is highly prevalent in our population. However, further longitudinal studies are need to better understand the severity and potential impact on quality of life.

\title{
INVESTIGATION OF OXIDATIVE STRESS STATUS AND NEUROPROTECTION BY VITAMIN E IN CHRONIC CEREBRAL HYPOPERFUSION-INDUCED NEURODEGENERATION IN RATS. Anil Kumar Saxena and Sayyada Sayeed
}

Department of Basic Medical Sciences, Kulliyyah of Medicine, International Islamic University, Kuantan, Malaysia.

Introduction: Reduced cerebral blood flow (CBF) is associated with aging and neurodegenerative disorders. CBFinduced neurodegeneration is related with the formation of reactive oxygen species (ROS), which is fatal to neurons at high concentrations.

Objective: To study the neuropathological consequences of a reduced CBF, a similar condition has been created in rats by common carotid artery occlusion (2 vessel occlusion, 2VO). Since vitamin E is known to be a potent antioxidant, the present study was designed to assess the effects of vitamin $\mathrm{E}$ as an antioxidant and neuroprotective agent in $2 \mathrm{VO}$ rat model.

Methodology: After acclimatization, twenty four Sprague Dawley rats weighing 200-250 g were equally divided into three groups. Group A - sham control, Group B-2VO, and Group C-2VO+E (treated daily with Vit E, $100 \mathrm{mg} / \mathrm{kg}$, orally following 2VO). On the 8th week, all the rats were euthanized and the hippocampi were isolated. Viable neuronal cell count in the hippocampal CA-1 region was estimated. The Isoprostane F2 (Iso-F2) levels were also measured in the brain homogenates to quantify the oxidative stress levels.

Results: There was significant difference in neuronal cell death in $2 \mathrm{VO}$ group as compared to sham group. In $2 \mathrm{VO}+\mathrm{E}$ rats, the viable neuronal cell count of the hippocampal CA-1 region was significantly higher $(\mathrm{p}<0.05)$ as compared to the 2VO group. Moreover, Iso-F2 levels in $2 \mathrm{VO}$ group was significantly higher $(\mathrm{p}<0.05)$ as compared to $2 \mathrm{VO}+\mathrm{E}$ group, implying high oxidative stress in $2 \mathrm{VO}$ group and reduction of oxidative stress levels in 2VO+E group.

Conclusion: This study clearly demonstrates the effectiveness of Vitamin $\mathrm{E}$ as a neuroprotective and antioxidative agent in chronic cerebral hypoperfusion induced-neurodegenerative in rats.

\section{MEDICAL STUDENTS’ KNOWLEDGE AND ATTITUDE ON ETHICAL ISSUES IN ANESTHESIA AND CRITICAL CARE \\ HO Ariff, AG Rasydan, $N$ Suhaila, AR Shahrir}

Kulliyyah of Medicine, International Islamic University Malaysia, 25200, Kuantan, Pahang, Malaysia

Introduction: One of the important skills that medical students should acquire before graduation is the ability to discuss and resolve common ethical dilemmas in clinical practice. Lectures, student seminars and small group discussions on ethical dilemmas are methods used to equip them with this important skill.

Objective: A pilot study was conducted on a group of fourth year students to evaluate their knowledge and attitude on common medical ethical dilemmas. 